\title{
Optimization of standard polymer-fullerene solar cells
} Glauco M. Santiago (IC), João Paulo de C. Alves(PG), Ana Flávia Nogueira(PQ)

\section{Abstract}

This work has the objective to prepare standard solar cells according to the literature. Polymer/fullerene solar cells were manufactured by spin-coating, using as polymer the P3HT and PCPDTBT, both conjugated thiophenes. Different changes in manufacturing process were tested, for instance, the implementation of additive and the use of calcium in the electrodes. Key words: Polymers, fullerene, solar cells.

\section{Introduction}

The interest in renewable sources of energy has led to many researches around the world. Among them the photovoltaic technology has emerged, whose devices convert solar energy in electric one. In the current scenario the amorphous silicon devices are the most popular photovoltaic cells. However, they are still expensive, because of their highly manufacture cost in processing the pure silicon. The organic photovoltaics arises bringing a promise of a cheaper alternative. The manufacturing of this cell type is easier and allows the deposit of the active layer in a flexible substract. ${ }^{1}$ Unfortunately, they still have problems as electron recombination and lower efficiencies. The complex film morphology is difficult to improve and has a great effect on the charge transport. The great challenge in organic photovoltaics is a morphological improvement to reduce the charge recombination. The bulk heterojunction consists in a nanocomposite of polymer (electron donor) and fullerene derivative (electron acceptor) that is casted in a thin film by spin-coating.

The objectives of this work are evaluate the effect of different parameters in manufacturing the organic BHJ solar cells, for instance, the nanocomposite concentration in solvent, thermal annealing, the metal used in electrodes and others variables to improve the cells and achieve the current standard of efficiency present in the literature.

\section{Results and Discussion}

The cells casting were prepared layer by layer. PEDOT:PSS was casted first layer above the ITO (Indium Tin Oxide), at $5000 \mathrm{rpm}$ for 1 minute, and then the active layer (nanocomposite), at $700 \mathrm{rpm}$ and 3 minutes. At the top of the cells the metal electrodes was evaporated.

In the first part of the research P3HT/PCBM cells were tested. There were two modifications in the cell structure that led to great changes in efficiency. The first one was the evaporation of a double layer of metal electrodes. Before that, only aluminum was used. After we used a thin layer of calcium and aluminum above. The implement of calcium led to better results than without it. It was proposed that the calcium has a work function more similar to the P3HT/PCBM than only the aluminum, allowing a better collection of charges. The second change was the addition of 1,8diiodooctane that led the cells from $1.68 \%$ of conversion efficiency to $2.36 \%$. The effect of the additive in morphology is clear. Some researchers believe that it created percolation networks that improve the charge carrier. ${ }^{2}$

In the second part it was tested organic cells in which PCPDTBT, an amorphous polymer, was used. The annealing $\left(150^{\circ} \mathrm{C}\right.$ for 10 minutes) of the active layer was tested. The results showed that there is not advantage in heating the active layer. This result is predictable, since the polymer is amorphous. Other important result is the metal used in the electrode. While the cells with P3HT have a good performance with calcium/aluminum electrode, PCPDTBT show better results with aluminum only. The presence of additive in the nanocomposite solution was not effective. The maximum efficiency, $1.56 \%$, of the cell was achieved without additive and annealing.

\section{Conclusions}

The crystalline polymer $\mathrm{P} 3 \mathrm{HT}$ achieved the standard efficiency previously reached in the lab, $2.36 \%$, however, lower than reported in the literature. The annealing part, calcium/aluminum electrode and the additive contributed to a better efficiency of the cell. On the other hand, the cells with PCPDTBT have a good result with aluminum electrode, but without additive or annealing, reaching $1.56 \%$.

\section{Acknowledgement}

The authors thank SAE, Fapesp, CNPq, Capes and INEO (National Institute of Organic Electronic/CNPq/FAPESP) for financial support and fellowships.

${ }^{1}$ Gunes S., Neugebauer H., Sariciftci N. S. Chem. Rev. 2007, 107, 1324.

${ }^{2}$ Ma W., Yang C., Gong X., Lee K., Heeger A. J. Adv. Funct. Mater., 2005, 15, 1617. 